\title{
Last Ice Age Global Ocean and Land Surface Temperatures: The EPILOG Initiative
}

The IMAGES EPILOG working group (www.images.cnrs-gif.fr/wgroups.html) was formed in December 1997 in order to establish a new and comprehensive look at the paleoenvironments of the last Ice Age. The major aim of this working group is to foster a revision of global reconstructions of the Ice Age Earth. This will be carried out by assembling international groups of paleoclimatologists to discuss and review the progress made for paleoenvironmental reconstructions for the last Ice Age during the last two decades since the completion of the CLIMAP (1981) LGM project.

Following this premise, an international workshop was held at the HANSE Institute for Advanced Studies, Delmenhorst, Germany, May 3-6, 1999, entitled "Global Ocean and Land Surface Temperatures during the last Ice Age". The workshop focused on the presentation and discussion of oceanic and continental temperature compilations using new or improved techniques for the estimation of absolute surface temperature values around 20,000 years before present. By bringing together marine and terrestrial paleoclimatologists, as well as paleoclimate modelers, the workshop provided an important step forward in our assessment of Last Ice Age climate. Discussion centered on glacial temperature data which have evolved significantly based on a suite of investigations over the past two decades since the presentation of CLIMAP (1981) paleotemperature maps. A new and comprehensive synthesis is essential both in its own right and in order to provide boundary conditions for climate models. Evaluation of the sensitivity of these climate models to changing boundary conditions is facilitated by comparison of modeling results with reconstructions of past features such as global surface temperatures.

The major tasks identified for this first EPILOG workshop were:

1. To establish an international consensus on the definition of the "Ice Age" or "LGM (Last Glacial Maximum)" time slice for orientation of any further syntheses considering this period.

2. To discuss and critically evaluate the potential of both commonly used

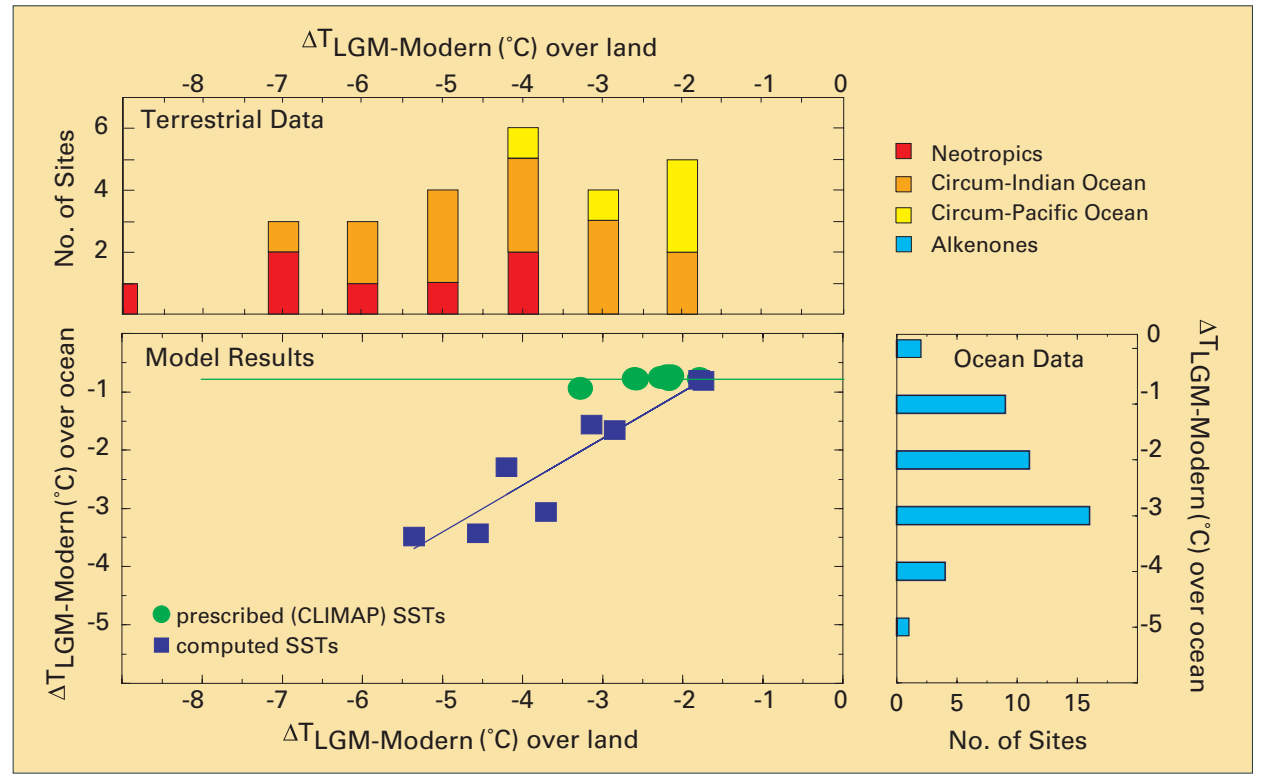

Figure 1: Comparison of Last Ice Age tropical temperature decrease for the continents (Farrera et al. $1999,32^{\circ} \mathrm{N}, 33^{\circ} \mathrm{S}$ ) and for the surface ocean (Rosell-Mele et al. 1998, alkenone data) with AGCM results either using prescribed CLIMAP (1981) sea surface temperatures (green dots) or by computing those (blue squares) coupling a surface mixed layer to the atmospheric general circulation model (Pinot et al. 1999) (Figure from Braconnot 2000).

and new techniques for estimation of past surface temperatures in the ocean and on the continents.

3. To initiate a new synthesis of Ice Age surface temperatures and to promote the generation of new global and regional compilations. In this context it was agreed that standard criteria are required for the application of the different paleotemperature methods as well as for procedures for data archiving in a manner which best facilitates access to the new data by the entire scientific community.

The above topics were comprehensively discussed in plenary and group discussions amongst 51 scientist from Australia, Canada, France, Germany, Great Britain, Spain, The Netherlands, and USA. Short individual oral and poster presentations introduced the entire audience to the need for finding a marine-terrestrial consensus for the Last Ice Age time slice, new and improved methods for paleotemperature estimation, and new regional and basin-wide data syntheses available for the ocean and the continents. Furthermore, the outcome of recent AGCM experiments for the LGM (e.g. PMIP) were presented. In this context, the discussion focused on differences in results amongst model runs with prescribed CLIMAP (1981) surface ocean temperatures and those employing new global data sets, e.g. the TEMPUS (Temperature Mapping using Unsaturated Ketons, Rosell-Méle et al. 1998) compilation, or, as shown in figure 1, those with computed surface ocean temperatures (PMIP, wwwpcmdi.llnl.gov/pmip/index.html, see also Pinot et al. 1999). New terrestrial temperature syntheses (e.g. Farrera et al. 1999) were also taken into account. International paleoclimate data archives such BIOME 6000, WDC-A and PANGAEA, including the IMAGES data curation, were also discussed. These archives have the potential to serve as electronic platforms for EPILOG time slice temperature data archiving, synchronisation and dissemination in the future.

The workshop participants agreed on a new definition of the Ice Age time slice which is defined by the period of maxiimum globally integrated ice volume in accordance with glacial eustatic sealevel low stand. As shown in figure 2, the EPILOG Last Ice Age time slice ranges from 19,000 to 23,000 cal years, centered at $21,000 \mathrm{cal}$ years BP, the time interval that spans the period where coral reefs and drilled coastal sediments 


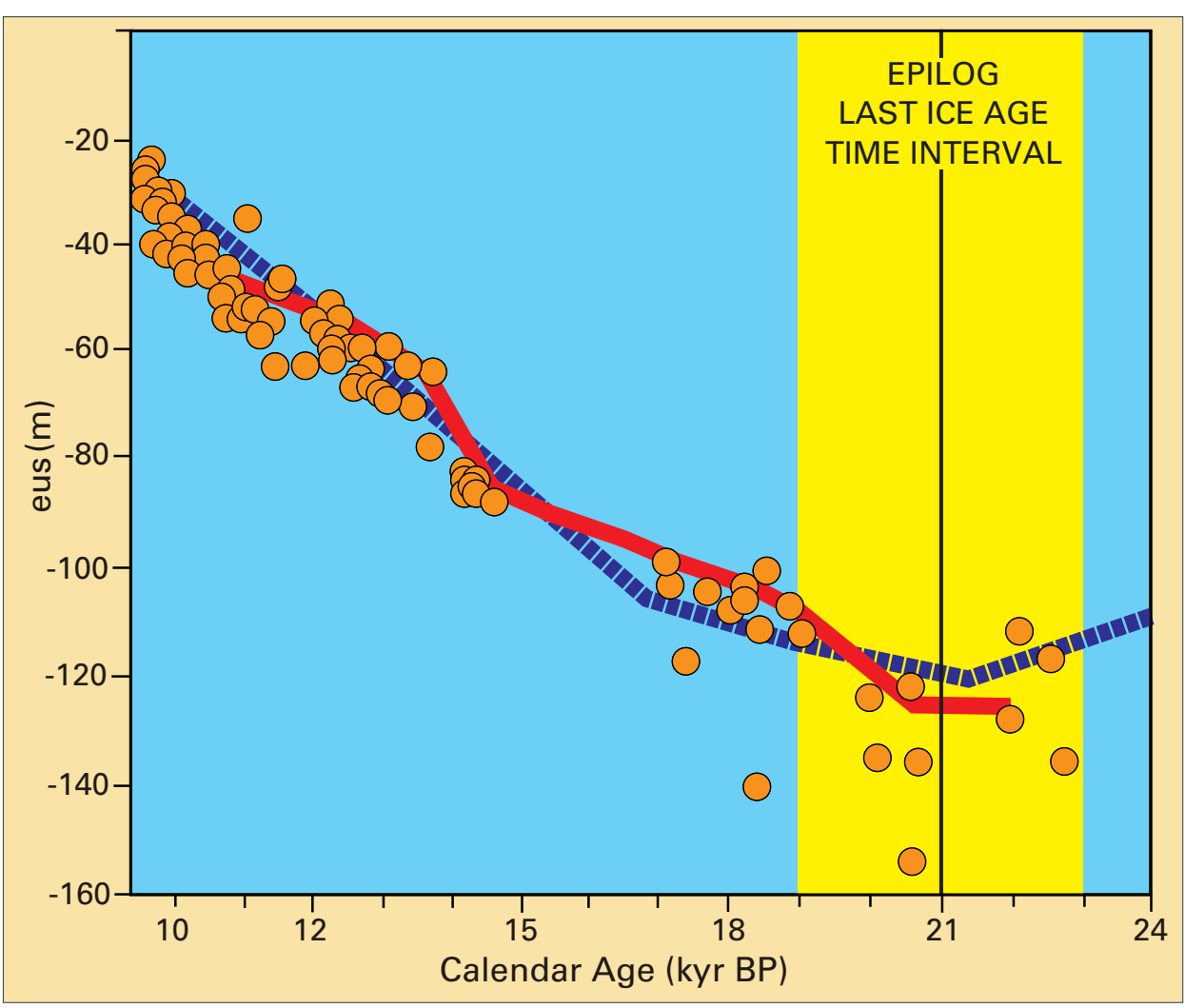

Figure 2. EPILOG consensus on the Last Ice Age time slice according to the maximun in relative lowering of eustatic sea level (red line) indicated by coral reef and coastal sediment core data (circles). Also shown is a theoretical sea level curve (blue dashed line) constructed by considering disintegration of nominal ice distribution for Antarctica, Western Northern Hemisphere, and Europe (modified from Fleming et al. 1998).

indicate greatest eustatic sea-level low stand (Fleming et al. 1998).

Since the rationale of this first EPILOG workshop evolved from ongoing international discussion on the uncertainties in the CLIMAP (1981) reconstructions of Last Ice Age surface ocean temperatures and sea-ice extent, a major part of the workshop time was spent on extensive discussions of the advantages and shortcomings of the different transfer function or modern analog techniques applied to sediment assemblages of planktonic foraminifera, diatoms and radiolaria, as well as to dinoflagellates. In this context it was heavily debated whether attributing the entire magnitude of variations in microfossil assemblages solely to a change in surface ocean temperature is appropriate or if changes in nutrient conditions and surface layer structure must be considered as major control mechanisms. As an alternative or complementary approach participants also examined the relatively new geochemical methods of alkenone paleothermometry and $\mathrm{Mg} / \mathrm{Ca}$ elemental ratios in foraminifera. The consensus was that these innovative methods already provide valuable paleotemperature information, however, their calibration should be improved by considering season and depth habitat of the living organisms which produce the organic markers or calcareous shells. For the alkenone method the european TEMPUS project and an international workshop held in Woods Hole in October 1999 dedicated to the application of alkenones in paleoceanography (Eglinton et al., subm.) have already promoted broad acceptance of the method. The use of elemental ratios in foraminiferal shells is, however, still at the beginning of a more general application in time slice temperature reconstructions at global or even regional scales. With respect to the latter it was therefore agreed to start a new initiative for an international laboratory calibration project on foraminiferal $\mathrm{Mg} / \mathrm{Ca}$ ratio as a quantitative paleotemperature indicator.

During the course of the workshop it became evident, that for the marine environment major efforts are still needed to step forward from various individual and research group initiatives producing regional or basin wide compilations to a new multiproxy global temperature synthesis for the Last Ice Age. As a first step in this direction is was envisaged that existing surface sediment data sets for the calibration of the various transfer equations should be made accessible to the different research groups applying these methods in different ocean basins for comparison. This should allow significant progress in statistical evaluation of the performance of different transfer-function and modern-analog techniques on the same calibration data set as well as comparison with results from the geochemical methods. These calibration-related and technical issues will be paralleled by initiatives already active in compiling new temperature for the Last Ice Age, such as the GLAMAP (Glacial Atlantic Ocean Mapping, wwww. pangaea.de/Projects/GLAMAP2000/) and TEMPUS projects.

For the continents a new synthesis for the Last Ice Age has recently been presented by Farrera et al. (1999). This "21 ka tropical paleoclimate synthesis" (www.bgc-jena.mpg.de/bgc_prenticel start1.html) focuses on the terrestrial evidence for tropical climates at 21,000 calendar yr BP. The synthesis includes, amongst other parameters, estimates of Mean Annual Ground Temperature (MAT) based on noble gas paleothermometry and speleothems and estimates of Mean Temperature of the Coldest Month (MTCO) based on pollen response. The latter is reconstructed applying "surface or modern" analog methods, shifts in treeline or montanevegetation belts using local lapse-rate calculations, and changes in pollenbased biome reconstruction using physiological temperature limits on individual biomes. In context of this synthesis EPILOG workshop discussions concentrated mainly on the problems in dating land records, on methods for land data regionalisation in order to produce temperature maps, and on better reconstruction of past lapse rates. It was further recommended to consider more marine sediment cores adjacent to desert and tropical rainforest regions as pollen archives which have the advantage of recording climate information from both environments in the same material, thus allowing direct evaluation of land-ocean linkages. This could also help to better constrain the timing of climate change on land due to often better age control in marine records. As is true for the marine 
community, a lot of compilation work and methodological harmonisations are still needed before global maps of Last Ice Age continent temperatures can be presented in near future.

In conclusion, the workshop served to set up an international agreement for the temporal range of the Last Ice Age time slice and provided a forum for extensive discussion of recently gained paleotemperature data and conflicting views on these new data. The workshop also served as a basis for new collaborative research between paleoclimatologists working on land and in the ocean, and modelers. Following this encouraging start in 1999, the second EPILOG workshop is planned to be held in October 2000 in order to reconcile "Global Ice Sheets and Sea Level during the Last Glacial Maximum" (www.images.cnrsgif.fr/workshops.html).

\section{References}

Braconnot P. Paleoclimate Modelling Intercomparison Project (PMIP). Proceedings of the third PMIP workshop, Canada, 4-8 October 1999, WCRP-111, WMO/TD-No. 1007, 271 (2000).

CLIMAP Project Members. Seasonal reconstruction of the Earth's surface at the last glacial maximum. Geol. Soc. Amer., Map and Chart Series, C36 (1981).

Eglinton T. et al. Alkenone biomarkers gain recognition as molecular paleoceanographic proxies. EOS (submitted).

Farrera I. et al. Clim. Dyn. 15, 823-856 (1999)

Fleming K. et al. Earth Planet. Sci. Lett. 163, 327-342 (1998).

Pinot S. et al. Clim. Dyn. 15, 857-874 (1999).

Rosell-Melé A. et al. EOS 79(33), 393-394 (1998).

\section{RalPh Schneider}

Fachbereich Geowissenschaften, Universität Bremen, Germany

rschneid@uni-bremen.de

\section{EDOUARD BARD}

CEREGE, CNRS, Université d' Aix-Marseille III, Aix-EnProvence, France ebard@cerege.fr

\section{Alan C. Mix}

Oregon State University, Corvallis OR, USA

mix@oce.orst.edu

\section{Integration of Ice-Core, Marine and Terrestrial Records (INTIMATE): A Core Project of the INQUA Commission on Paleoclimate}

The abrupt, millennial-scale climatic fluctuations of the Last Glacial Termination are among the most intensivelystudied features of the late Quaternary. High-resolution records of this period are available from the terrestrial, marine and polar ice realms. Careful scrutiny of this collective evidence may well hold the key to understanding complex feedbacks in land-sea-ice interactions, and to establishing the mechanisms behind some of the sub-Milankovitch climatic fluctuations that are so prominent in the Greenland ice-core records. The INTIMATE programme, launched at the XIV th INQUA Congress held in Berlin in 1995, was established to encourage collaboration between members of the ice-core, marine and terrestrial 'communities' in order to synthesise the large number of high-resolution stratigraphical records of the Last Glacial Termination that are now available from the North Atlantic region. Subsidiary aims included establishing procedures for more precise dating and more accurate correlations of regional and / or site data-sets, and testing the notion that the North Atlantic limb of the ocean conveyor was the major driver of abrupt climatic changes in the North Atlantic region during the Last Glacial Termination. The main outcome of this collaborative effort so far has been the formulation of a new stratigraphic scheme for the North Atlantic region: an 'event stratigraphy' for the Last Glacial Termination, based on the stratotype of the GRIP ice-core record (Björck et al., 1998; Walker et al., 1999). This is considered to offer a more satisfactory alternative to conventional stratigraphical procedures for inter-regional data syntheses, as well as for the assessment of the degree of synchroneity of short-term climatic events. The scheme is gradually being adopted by more and more research groups to underpin regional data-syntheses, and to effect more precise inter-regional correlations (Walker et al., in prep.).
The INTIMATE programme is now entering a new phase. Following recommendations made at a workshop held at the $\mathrm{XV}^{\text {th }}$ INQUA Congress in Durban in August 1999, the INTIMATE programme is to enlarge its focus to consider the evidence not only from the North Atlantic region, but also from the South Atlantic and Mediterranean regions. The aims are to compare the timing and magnitude of millennialscale climatic fluctuations during the Last Glacial Termination between these three major regions. The details of how the programme will proceed with this task will be discussed at the next international workshop of INTIMATE, which will be held in Kangerlussuaq, Greenland in August 2000. Participation in the work of INTIMATE is open to any scientist with interests in, and / or data pertinent to, the aims of INTIMATE. Individuals or research groups who have developed detailed paleo-environmental reconstructions for the Last Glacial Termination in the Atlantic region, especially well-dated records suitable for calibration to the calendar time-scale, are encouraged to participate in the programme by contacting the INTIMATE Secretary, Wim Hoek, or the INTIMATE Co-ordinator, John Lowe.

\section{References \\ Biörck et al. 1998, Journal of Quaternary Science 13 283-292. \\ Walker et al. 1999 Quaternary Science Reviews 18, 1143-1150. \\ Walker, et al. (in prep.) Quaternary Science Reviews.}

\section{W.Z. Hoek}

Department of Quaternary Geology and Geomorphology, Vrije Universiteit, Amsterdam, The Netherlands hoew@geo.vu.nl http://www.geo.vu.nl/ quageo/staff/hoew.html http://www.geo.vu.nl/ intimate/ 